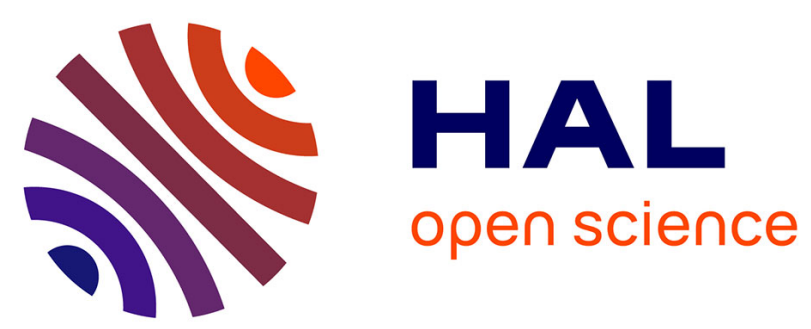

\title{
Retrospective assessment of pregnancy exposure to particulate matter from desert dust on a Caribbean island: could satellite-based aerosol optical thickness be used as an alternative to ground PM10 concentration?
}

Stephane Tuffier, Erika Upegui, Christina Raghoumandan, J.-F. Viel

\section{To cite this version:}

Stephane Tuffier, Erika Upegui, Christina Raghoumandan, J.-F. Viel. Retrospective assessment of pregnancy exposure to particulate matter from desert dust on a Caribbean island: could satellite-based aerosol optical thickness be used as an alternative to ground PM10 concentration?. Environmental Science and Pollution Research, 2021, 28 (14), pp.17675-17683. 10.1007/s11356-020-12204-x . hal03131163

\author{
HAL Id: hal-03131163 \\ https://hal.science/hal-03131163
}

Submitted on 22 Feb 2021

HAL is a multi-disciplinary open access archive for the deposit and dissemination of scientific research documents, whether they are published or not. The documents may come from teaching and research institutions in France or abroad, or from public or private research centers.
L'archive ouverte pluridisciplinaire HAL, est destinée au dépôt et à la diffusion de documents scientifiques de niveau recherche, publiés ou non, émanant des établissements d'enseignement et de recherche français ou étrangers, des laboratoires publics ou privés. 
1 Stéphane Tuffier ${ }^{1}$, Erika Upegui ${ }^{2}$, Christina Raghoumandan ${ }^{3}$, Jean François Viel ${ }^{1^{*}}$ for the

2 BrumiSaTerre research group

3

4

5 Retrospective assessment of pregnancy exposure to particulate matter from desert dust

6 on a Caribbean island: could satellite-based aerosol optical thickness be used as an

7 alternative to ground $\mathbf{P M} 10$ concentration?

8

9

10

$11{ }^{1}$ Univ Rennes, CHU Rennes, Inserm, EHESP, Irset (Institut de recherche en santé,

12 environnement et travail) - UMR_S 1085, F-35000 Rennes, France

$13{ }^{2}$ Faculty of Engineering, Universidad Distrital Francisco José de Caldas, CP 110001 Bogota,

14 Colombia

$15{ }^{3}$ Gwad'Air, Air quality monitoring agency, F-97170 Petit-Bourg, France

16

17 * Correspondence: jean-francois.viel@univ-rennes1.fr, phone: +33 299289827 
Abstract

19 Desert dust transported from the Saharan-Sahel region to the Caribbean Sea is responsible for peak exposures of particulate matter (PM). This study explored the potential added value of

21 satellite aerosol optical thickness (AOT) measurements, compared to the PM concentration at 22 ground level, to retrospectively assess exposure during pregnancy. MAIAC MODIS AOT 23 retrievals in blue band $\left(\mathrm{AOT}_{470}\right)$ were extracted for the French Guadeloupe archipelago. $\mathrm{AOT}_{470}$ 24 values and $\mathrm{PM}_{10}$ concentrations were averaged over pregnancy for 906 women (2005-2008). Regression modeling was used to examine the $\mathrm{AOT}_{470}-\mathrm{PM}_{10}$ relationship during pregnancy, and test the association between dust exposure estimates and preterm birth. Moderate agreement was shown between mean $\mathrm{AOT}_{470}$ retrievals and $\mathrm{PM}_{10}$ ground-based measurements during pregnancy $\left(\mathrm{R}^{2}=0.289\right)$. The magnitude of the association between desert dust exposure and

29 preterm birth tended to be lower using the satellite method compared to the monitor method.

30 The latter remains an acceptable trade-off between epidemiological relevance and exposure 31 misclassification, in areas with few monitoring stations and complex topographical/ 32 meteorological conditions, such as tropical islands.

33

34 Keywords: desert dust; aerosol optical thickness; particulate matter $\leq 10 \mu \mathrm{m}$; satellite imagery; 35 MAIAC algorithm; epidemiology 
Declaration

37

\section{Ethics approval and consent to participate}

The TIMOUN study was approved by the Guadeloupean Ethics Committee for studies involving human subjects. Written informed consent was provided by each participant.

\section{Consent for publication}

Not applicable.

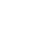

\section{Availability of data and materials}

The dataset used and analyzed during the current study is available from the corresponding author on reasonable request.

(1)

\section{Competing interests}

The authors declare that they have no competing interests.

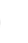

\section{Funding}

2 This work was funded by the French National Research Program for Environmental and

Occupational Health of ANSES (EST-2016/1/015).

\section{Author contributions}

6 S.T. analyzed and interpreted the data; E.U. performed the satellite data management and

7 processing; C.R. provided the air quality data; JFV conceived and planned the study,

8 interpreted the data, and prepared the first draft of the manuscript on which all coauthors

59 commented. 
61 The authors are grateful to Yujie Wang and Alexei Lyapustin from the NASA Center for

62 Climate Simulations for providing MCD19A2 data and valuable advice. The authors thank the

63 gynecologists, obstetricians, ultra-sonographers, midwives, pediatricians, and families who

64 participated in the TIMOUN study.

65

\section{Authors' information}

67 BrumiSaTerre research group: Gulen Ayhan, Séverine Ferdinand, Céline Garbin, Stéphanie

68 Guyomard, Philippe Kadhel, Fabien Mercier, Léah Michineau, Luc Multigner, Philippe

69 Quénel, Christian Raghoumandan, Antoine Talarmin, Stéphane Tuffier, Erika Upegui, and 70 Jean-Francois Viel. 


\section{Introduction}

73 On a global scale, most atmospheric particles are emitted by natural sources, mineral dust being

74 the second most abundant component (after sea-spray derived aerosols). The Sahara and Sahel regions in Northern Africa generate the most dust in terms of emissions (Querol et al. 2019). Most African dust particles travel westwards over the Atlantic over long distances and affect areas in the Caribbean and the Americas, generating peak exposures to particulate matter (PM) in these downwind regions. The dust plume extension varies throughout the year depending on the displacement of the Inter-Tropical Convergence Zone (Prospero et al. 1981), inducing marked seasonality (emissions peaking in spring and summer). Desert dust typically mixes with locally- or regionally-emitted PM, but the median desert dust mass diameter was found to be $3.2 \mu \mathrm{m}$ in Barbados and $3.5 \mu \mathrm{m}$ in Puerto Rico (Reid et al. 2003).

Accurately assessing desert dust exposure in the Caribbean region is challenging due to sparse ground monitoring networks. Conversely, satellite remote sensing, in terms of aerosol optical thickness (AOT), has provided new methods to monitor PM air quality with fine spatial and temporal resolution, since the launch of the Moderate Resolution Imaging SpectroRadiometer (MODIS) (Xiao et al. 2017). AOT is based on the impedance of light transmission by the absorption or scattering of light by aerosols through the vertical column of the atmosphere from the ground to the satellite sensor (Duncan et al. 2014). However, satellite data may be compromised by the non-random absence due to cloud cover, high surface reflectance (desert and snow-covered surfaces), and extremely high aerosol loading, which can be misclassified as clouds (Lee et al. 2012; Di et al. 2016). Thus, AOT data may not be available for a large fraction of days (non-retrieval days). 
A recent algorithm (released in 2018), called "Multi-Angle Implementation of Atmospheric Correction" (MAIAC C6.1), has greatly improved MODIS AOT retrievals with a more accurate detection of cloudy and clear-sky areas, enabling it to produce AOT data for partially cloudy days (Lyapustin et al. 2018). It uses time series (up to 16 days) analysis to exploit multiangle viewing effects and image processing to derive the surface bidirectional reflectance function. MAIAC relies on dynamic land-water-snow classification from daily observations to select the proper processing path. MAIAC AOT retrieval in blue band $\left(\mathrm{AOT}_{470}\right)$ is a unitless value ranging from 0 (indicating extremely clear weather with maximum visibility) to a maximum of 4.0. The fine spatial resolution $(1 \mathrm{~km})$ and high accuracy of MAIAC AOT 470 makes it possible to characterize local-scale aerosol heterogeneity.

104 The derivation of surface PM from satellite AOT is always challenging because of the effect 105 of various factors (such as aerosol composition, relative humidity, the vertical profile of the particle concentration, and the altitude of the aerosol layer) (Duncan et al. 2014). The most widely used method is empirical analysis, in which in situ PM measurements are regressed with the corresponding satellite AOT value, adjusting for meteorological data and land-use variables, 109 in the framework of linear mixed effects models. MAIAC AOT retrievals have been used to 110 estimate ground PM distributions and support air pollution epidemiological studies in the USA 111 and Mexico (Di et al. 2016; Hu et al. 2014; Just et al. 2015; Strickland et al. 2016). However, 112 the AOT-PM relationship is spatially and temporally inhomogeneous. Thus, continued research 113 is needed for various regions of the world, especially in locations where few surfaced-based 114 PM measurements have been obtained, to date (Chen et al. 2013).

115 We recently showed an association between maternal exposure during pregnancy to desert 116 dust and preterm birth in the French Guadeloupe archipelago (an outermost region of the 117 European Union situated in the Caribbean basin) (Viel et al. 2019). We assessed exposure 
118 through $\mathrm{PM} \leq 10 \mu \mathrm{m}\left(\mathrm{PM}_{10}\right)$ concentrations recorded at the sole (urban) background air quality 119 monitoring station of Guadeloupe, located in Pointe-à-Pitre (central part of the Guadeloupe 120 archipelago), regardless of the location of the woman's residence. However, spatial 121 heterogeneity in terms of exposure can be supposed, as concentrations may be lower on the 122 island's leeward (i.e., western) side, which is partially sheltered from trade winds by the La 123 Soufrière volcano (1,467 m high, located in Basse-Terre, the south-western part of 124 Guadeloupe). This presumed spatial variability of air pollutants related to topography (and also 125 local micro sources) may not be captured by a single background air quality monitoring station, 126 and non-differential misclassification may occur.

127 To our knowledge, only two other studies have relied on satellite AOT data to estimate 128 average exposure to $\mathrm{PM}_{2.5}$ during pregnancy, but at the lower spatial resolution of a $10 \mathrm{x} 10$ 129 km grid (across Connecticut and Massachusetts - USA), using daily calibration of PM ground 130 measurements from a dense network of monitoring stations (Kloog et al. 2012; Hyder et al. 131 2014). The Guadeloupe archipelago poses, however, several unique challenges in terms of air132 pollution assessment, both topographically and meteorologically. Land use is heterogeneous, 133 and the islands feature a complex topography (abrupt elevation changes and rugged terrain) and 134 a humid subtropical climate (tempered by trade winds), with frequent cloud cover and a long 135 rainy season (from July to November).

136 This feasibility study explored the potential added value of MAIAC AOT retrievals, 137 compared to the PM concentration at ground level, to retrospectively assess exposure during 138 pregnancy for epidemiological purposes in a tropical island environment. 


\section{Materials and methods}

\section{Study domain and population}

144 Guadeloupe, with a population of 450,000 inhabitants, is an archipelago located in the Leeward 145 Islands in the Caribbean. Pregnancies of the 909 women enrolled in the TIMOUN mother-child 146 cohort occurred during the time period from March 30, 2004 to July 30, 2007 (last delivery on 147 April 28, 2008) (Viel et al. 2019). Home addresses during pregnancy were geocoded, showing 148 a median distance from the air quality monitoring station of $13.03 \mathrm{~km}$, as the crow flies (Fig. 1).

\section{Ground PM measurements}

152 The assessment of exposure has been fully described elsewhere (Viel et al. 2019). Briefly, mean 153 daily $\mathrm{PM}_{10}$ concentrations $\left(\mu \mathrm{g} / \mathrm{m}^{3}\right)$ recorded at the Pointe-à-Pitre monitoring station were 154 provided by Gwad'Air (the official air quality monitoring agency for Guadeloupe) from 2005 155 to 2008 (no data were available before 2005). $\mathrm{PM}_{10}$ concentrations were measured using the 156 Thermo Scientific Tapered Element Oscillating Microbalance (TEOM) models 1400ab and 157 1400-FDMS. The TEOM is widely used in air quality programs in Europe and the United States 158 and qualifies as a U.S. Environmental Protection Agency equivalent method 159 (http://www.epa.gov/ttn/amtic/criteria.html). No PM 2.5 concentrations were measured and no 160 other air quality monitoring station was operating in the Guadeloupe archipelago during this 161 period.

\section{MODIS AOT retrievals}


165 This study relied on MAIAC AOT 470 retrievals from both the Aqua and Terra satellites. We used the MCD19A2 Version 6 data product, a MODIS Terra and Aqua combined MAIAC AOT gridded dataset, containing 13 daily atmospheric properties at $1 \mathrm{~km}$ pixel resolution, in 1,200 x 1,200-km local tiles. MCD19A2 data were provided by the NASA Center for Climate Simulations for the local tile HH12VV07 for the years 2005 to 2008. $\mathrm{AOT}_{470}$ retrievals were extracted from each atmospheric properties file. Pixel maps were orthorectified using NASA SeaDAS 7.5.1 software, the Global Earth Topography and Sea Surface Elevation (at 30 arcsecond resolution - GETASSE30) model, the linear polynomial method, and five photo-identified ground control points (extracted from ESRI World Imagery). Positional accuracy was assessed through the root-mean-square error (RMSE), representing an averaged difference between the rectified imagery and ground truth. RMSE was $0.00812^{\circ}$ (901.6 m) in latitude, and $0.00996^{\circ}(1108.7 \mathrm{~m})$ in longitude, respecting the general rule of an RMSE equivalent to the size of a pixel in the output image. We applied a sliding-window spatial 178 filter, replacing the center value in the $3 \times 3$ window with the median of the nine pixel values 179 in the window.

180 As a result, we obtained daily Aqua and Terra $\mathrm{AOT}_{470}$ retrievals for the terrestrial part of the 181 Guadeloupe archipelago (1,054 pixels) for the period from 2005 to 2008. We primarily used 182 the Aqua $\mathrm{AOT}_{470}$ measurements, estimating their missing values from the Terra $\mathrm{AOT}_{470}$ values 183 (if available) using an adjustment factor. This factor was equal to the ratio of the average Aqua $184 \mathrm{AOT}_{470}$ to Terra $\mathrm{AOT}_{470}$ for the days for which both the Aqua and Terra measurements were 185 available (Lee et al. 2012). Finally, we overlaid a map of the mothers' residence onto the grid cell maps to obtain a median smoothed $\mathrm{AOT}_{470}$ value for each place of residence and each day. To avoid temporal 
mismatch between the $\mathrm{PM}_{10}$ and $\mathrm{AOT}_{470}$ values, the time period spanned from January 1, 2005

189 (first $\mathrm{PM}_{10}$ concentration available) to April 28, 2008 (last delivery in the TIMOUN cohort)

190 (1,214 days).

192 Statistical analyses

194 We averaged the $\mathrm{AOT}_{470}$ values and $\mathrm{PM}_{10}$ concentrations over each pregnancy to assess desertdust exposure (for the 234 pregnancies which started in 2004, the means were calculated for their 2005 component). Then, we considered topographical and land-cover contrasts to control

197 for spatial variability of the $\mathrm{AOT}_{470}$ values for exposure. First, we split the Guadeloupe territory 198 into the windward and leeward sides of La Soufrière volcano to investigate the potential effect 199 of trade winds. Second, we distinguished the capital city (Pointe-à-Pitre) and its suburbs (as the 200 city spreads beyond the old municipal boundary lines) from the rest of Guadeloupe because a 201 recent study showed lower correlations between MAIAC AOT retrievals and ground-truth data 202 over bright areas than those over vegetated areas (Martins et al. 2017). We used linear 203 regression modeling with average $\mathrm{AOT}_{470}$ values during pregnancy as the dependent variable 204 and the geographical contrast (windward vs. leeward) as the independent variable. We 205 introduced time (autumn-winter semester vs. spring-summer semester of each year of the study 206 period, defined a priori as the semester including week 14 of the corresponding pregnancy) and 207 space (geographical contrast) $\mathrm{x}$ time (semester) interaction terms in multivariate models, as 208 pregnancies occurred throughout the study period and as desert-dust episodes can vary between 209 years. We created a similar model but with the urbanization contrast as the independent 210 variable. Finally, the association between the average $\mathrm{AOT}_{470}$ value and $\mathrm{PM}_{10}$ concentration 211 during pregnancy was examined by univariate linear regression. 
As external validation, a multivariate logistic regression model was used to estimate the association between the AOT-based desert dust exposure and preterm birth while adjusting for

214 numerous individual risk factors, as in our previous $\mathrm{PM}_{10}$-based analysis (place of inclusion, 215 maternal age, marital status, years of education, body mass index, parity, prior preterm birth, 216 prior miscarriage, prior induced abortions, lupus, asthma, chronic hypertension, gestational 217 weight gain, gestational hypertension, gestational diabetes, urinary tract infection, sex of the 218 newborn) (Viel et al. 2019). To compare the impact of this exposure proxy with the PM10-based 219 proxy, we calculated the odds ratios (ORs) per standard deviation (SD) change (0.037).

220 Statistical analyses were performed using $\mathrm{R}$ software (R Foundation for Statistical 221 Computing, Vienna, Austria, 2020).

\section{Results}

\section{Descriptive results}

During the 1,214-day study period, $\mathrm{PM}_{10}$ concentrations ranged from 9.3 to $157.0 \mu \mathrm{g} / \mathrm{m}^{3}$

228 (median: $21.0 \mu \mathrm{g} / \mathrm{m}^{3}$ ), with data missing for 55 days because of routine maintenance or 229 mechanical failure. Of the 1,279,556 expected $\mathrm{AOT}_{470}$ values (1,054 pixels x 1,214 days), 230 only 252,630 were retrieved (19.7\%), ranging from 0.002 to 0.964 (median: 0.199 ).

231 Plotting of all daily mean values against the day-of-the-year yielded much the same 232 irregular picture for both series (Fig. 2). The month-to-month variation (reflecting more 233 frequent dust outbreaks in the late spring - early summer) was not similar between years. 234 Averaging the available daily measures over the entire pregnancy showed the mean $\mathrm{PM}_{10}$ 235 concentrations to range from 13.2 to $34.9 \mu \mathrm{g} / \mathrm{m}^{3}$ (median: $28.2 \mu \mathrm{g} / \mathrm{m}^{3}$ ) and the mean AOT $_{470}$ 
236 values to range from 0.042 to 0.283 (median: 0.189 ). Three women were excluded because of

237 childbirth in early January 2005 and the absence of daily AOT470 estimates during this short

238 period of observation.

\section{Spatial variability}

242 The mean $\mathrm{AOT}_{470}$ values during pregnancy, according to the place of residence of the mothers,

243 are presented in Table 1 . We plotted the mean AOT $_{470}$ retrievals during pregnancy, over

244 Guadeloupe across time to examine both spatial variability and potential space $\mathrm{x}$ time 245 interactions (Fig. 3).

246 Univariate analysis showed higher values on the windward (eastern) side of the island ( $p<$

$\left.24710^{-4}\right)$. However, the spatial difference was no longer found when adjusting for time period $(p=$ $2480.30)$, whereas the difference between all semesters was significant $\left(p<10^{-15}\right)$, as well as three 249 space $\mathrm{x}$ semester interactions $(p<0.05)$. Finally, we found no significant difference in the mean

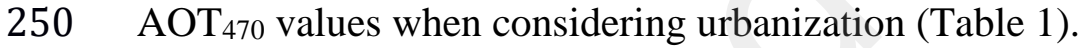

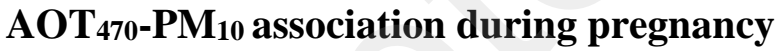

254 Average $\mathrm{AOT}_{470}$ values showed moderate agreement with average $\mathrm{PM}_{10}$ ground-based 255 measurements (both calculated during pregnancy), with a squared correlation coefficient ( $\mathrm{R}^{2}$ ) 256 of 0.289 (slope 0.006, $p<10^{-15}$ ) (Fig. 4). The offset (equal to 0.005) did not differ 257 significantly from zero $(p=0.50)$. 
261 The crude and adjusted associations between $\mathrm{AOT}_{470}$-based exposure estimates and preterm

262 birth were very similar and elevated, but not significantly $(\mathrm{OR}=1.19,95 \% \mathrm{CI}=0.98-1.46$,

$263 p=0.08$, and $\mathrm{OR}=1.18,95 \% \mathrm{CI}=0.95-1.47, p=0.14$, in univariate model and multivariate 264 model, respectively).

Discussion

268 Here, we used recent high-resolution (1 km) AOT MODIS data based on the MAIAC

269 algorithm to assess past exposure (2005-2008) of pregnant women to desert dust and to check

270 its accuracy for epidemiological purposes.

271 The mean coverage of AOT values in Guadeloupe was poor (19.7\%), due to cloud cover

272 and unfavorable surface conditions. This is similar to the fraction (19.8\%) reported for

273 another complex terrain (Switzerland) (de Hoog et al. 2018) and slightly lower than results

274 reported for Taiwan (a much broader, more highly populated, and more industrialized island 275 than Guadeloupe but sharing a similar climate), with a mean overall coverage of Terra and 276 Aqua AOT values of 23.0\% (Jung et al. 2018). Despite continuous improvements of cloud 277 detection and atmospheric corrections over inlands and coastal water, missing MAIAC AOT 278 values due to cloud cover and bright surfaces is still a major limitation and challenge. The 279 MAIAC algorithm consistently misses a specific type of cloud cover (moderately thin and 280 homogeneous cumulus) over water, generating high AOT values (Lyapustin et al. 2018), and 281 MAIAC retrievals over bright surfaces are generally poorer than those over vegetated areas 282 (Chen et al. 2013). The high concentration of the Guadeloupean population in coastal areas is 283 another challenge. Indeed, because of the inherent uncertainties of gridding on the coastline 
284 (and the different land/water processing paths), the area within $2 \mathrm{~km}$ of the coastline may

285 contain frequent artifacts in cloud mask (usually over-detection) and AOT (higher values)

286 (Lyapustin et al. 2018), potentially biasing individual exposure estimates.

287 In Guadeloupe, the maximum AOT value was 0.964, in agreement with results from South 288 America, where 98\% of AOT values ranged from 0.01 to 1.0 (Martins et al. 2017).

289 Unfortunately, we could not use aerosol optical measurements from the local AERONET site 290 as "ground trust" in satellite retrieval calibration and aerosol characterization because of 291 numerous missing data during the study period (695 of 1214 days).

292 Consistent with our epidemiology-oriented approach, also shared by other researchers

293 (Kloog et al. 2012; Hyder et al. 2014), available daily AOT 470 estimates were averaged to 294 pregnancy values for the place of residence of each woman (with some uncertainty because of 295 the missing retrievals).We found little evidence of geographical variability for $\mathrm{AOT}_{470}$ retrievals during pregnancy over Guadeloupe when considering a windward/leeward or

297 urbanization contrast. The correlation found in this study $(\mathrm{R}=0.537)$ between average $298 \mathrm{AOT}_{470}$ retrievals and $\mathrm{PM}_{10}$ ground-based measurements during pregnancy was moderate.

299 This could be partially due to the fact that satellite-derived AOT is a measure of light 300 attenuation in the column, which is affected by ambient conditions, whereas $\mathrm{PM}_{10}$ is a 301 measure of dry particle mass near the surface. However, the regression line passing through 302 the origin suggests that the same phenomenon is measured by both metrics.

303 Quantifying the fraction of $\mathrm{PM}_{10}$ concentrations attributed to the African dust outbreak for 304 the days with identified African influence was unfortunately out of reach because particle 305 filters were no longer available for the study period. However, Guadeloupe anthropogenic 306 particle pollution is low (approximately $20 \mu \mathrm{g} / \mathrm{m}^{3}$ ), because of the absence of heavy industries 307 and the year-round presence of trade winds. As a result, desert dust natural pollution is the 
main factor affecting $\mathrm{PM}_{10}$ data (Euphrasie-Clotilde et al. 2017). This is the reason why the

309 local air quality monitoring agency classifies desert dust episodes according to $\mathrm{PM}_{10}$

310 concentrations: light, 28-38 $\mu \mathrm{g} \mathrm{PM}_{10} / \mathrm{m}^{3}$; moderate, 39-54 $\mu \mathrm{g} \mathrm{PM}_{10} / \mathrm{m}^{3}$ ); intense, $\geq 55 \mu \mathrm{g}$

$311 \quad \mathrm{PM}_{10} / \mathrm{m}^{3}$ (Viel et al. 2019).

312 Unfortunately, a number of geo-climatic features distinguish the Guadeloupe archipelago

313 (territory of rather limited size, complex topography, humid sub-tropical weather and

314 maritime surroundings), precluding any comparison with results reported in Connecticut and

315 Massachusetts - USA (Kloog et al. 2012; Hyder et al. 2014). In Guadeloupe, the magnitude of

316 the association between desert dust exposure and preterm birth tended to be lower using the

317 satellite method compared to the monitor method. Indeed, the crude and adjusted ORs per SD

318 change for the $\mathrm{PM}_{10}$-based proxy were significantly increased $(\mathrm{OR}=1.36,95 \% \mathrm{CI} 1.07,1.73$,

$319 p=0.01$, and OR 1.40, 95\% CI 1.08, 1.81, $p=0.01$, respectively) (Viel et al. 2019). One

320 explanation could be that when AOT retrieval is successful, the variability of PM

321 concentrations is dominated by its temporal component and concentration levels tend to be

322 spatially smooth (Liu et al. 2009). Because of the high proportion of non-retrieval days

323 (80.3\%), the satellite method cannot compete regarding the temporal dimension, attenuating

324 associations towards the null.

\section{Conclusion}

328 Given the above-mentioned limitations, the AOT-based proxy does not appear to be more

329 appropriate than the PM-based proxy to retrospectively assess the exposure of pregnant

330 women to desert dust in the Caribbean. We believe that the conventional estimation of $\mathrm{PM}_{10}$

331 exposure (assigning ground-level measurements to populations within a specified distance of 
332 the monitoring station) remains an acceptable trade-off between epidemiological relevance

333 and exposure misclassification, given the specific local conditions of the Guadeloupe, the

334 spatial homogeneity of the AOT 470 retrievals, and the short median distance, as the crow flies,

335 between the places of residence and the monitoring station. More generally, estimating

336 historical levels of PM concentrations on a small spatial and temporal scale to support

337 epidemiological studies on the air pollution related health burden is still challenging, at least

338 in areas with few monitoring stations and complex topographical/ meteorological conditions,

339 such as tropical areas. 


\section{References}

342 Chen BB, Sverdlik LG, Imashev SA, Solomon PA, Lantz J, Schauer JJ, Shafer MM, 343 Artamonova MS, Carmichael G (2013) Empirical relationship between particulate matter 344 and aerosol optical depth over Northern Tien-Shan Central Asia. Air Qual Atmos Health 6: $345 \quad 385-396$.

346 Di Q, Kloog I, Koutrakis P, Lyapustin A, Wang Y, Schwartz J (2016) Assessing PM 2.5

347 exposures with high spatiotemporal resolution across the continental United States. 348 Environ Sci Technol 50:4712-4721.

349 Duncan BN, Prados AI, Lamsal LN, Liu Y, Streets DG, Gupta P, Hilsenrath E, Kahn RA, 350 Nielsen JE, Beyersdorf AJ, Burton SP, Fiore AM, Fishman J, Henze DK, Hostetler CA, 351 Krotkov NA, Lee P, Lin M, Pawson S, Pfister G, Pickering KE, Pierce RB, Yoshida Y, 352 Ziemba LD (2014) Satellite data of atmospheric pollution for US air quality applications: examples of applications summary of data end-user resources answers to FAQs and common mistakes to avoid. Atmos Environ 94:647-662.

355 Euphrasie-Clotilde L, Molinié J, Feuillard T, Brute F (2017) The relationship between coastal 356 West African dust level and Caribbean island dust. In: David AGD, Longhurst JWS, 357 Brebbia CA, Barnes J (eds) WIT transactions on ecology and the environment. WIT Press, $358 \quad$ Southampton, pp 121-128.

359 de Hoogh K, Heritier H, Stafoggia M, Künzli N, Kloog I (2018) Modelling daily PM 25 360 concentrations at high spatio-temporal resolution across Switzerland. Environ Pollut $361 \quad 233: 1147-1154$. 
Hu X, Waller LA, Lyapustin A, Wang Y, Liu Y (2014) Ten-year spatial and temporal trends of $\mathrm{PM}_{2.5}$ concentrations in the southeastern US estimated using high-resolution satellite data. Atmos Chem Phys 14:6301-6314.

Hyder A, Lee HJ, Ebisu K, Koutrakis P, Belanger K, Bell ML (2014) PM2.5 exposure and birth outcomes: use of satellite- and monitor-based data. Epidemiology 25:58-67.

Jung CR, Hwang BF, Chen WT (2018) Incorporating long-term satellite-based aerosol optical depth localized land use data and meteorological variables to estimate ground-level $\mathrm{PM}_{2.5}$ concentrations in Taiwan from 2005 to 2015. Environ Pollut 237:1000-1010.

Just AC, Wright RO, Schwartz J, Coull BA, Baccarelli AA, Tellez-Rojo MM, Moody E, Wang Y, Lyapustin A, Kloog I (2015) Using high-resolution satellite aerosol optical depth to estimate daily $\mathrm{PM}_{2.5}$ geographical distribution in Mexico City. Environ Sci Technol 49:8576-8584.

Kloog I, Melly SJ, Ridgway WL, Brent A, Coull BA, Schwartz J (2012) Using new satellite based exposure methods to study the association between pregnancy $\mathrm{PM}_{2.5}$ exposure premature birth and birth weight in Massachusetts. Environ Health 11:40.

Lee HJ, Coull BA, Bell ML, Koutrakis P (2012) Use of satellite-based aerosol optical depth and spatial clustering to predict ambient $\mathrm{PM}_{2.5}$ concentrations. Environ Res 118:8-15.

Liu Y, Paciorek CJ, Koutrakis P (2009) Estimating regional spatial and temporal variability of $\mathrm{PM}_{2.5}$ concentrations using satellite data meteorology and land use information. Environ $381 \quad$ Health Perspect 117:886-892.

382 Lyapustin A, Wang Y, Korkin S, Huang D (2018) MODIS Collection 6 MAIAC Algorithm $383 \quad$ Atmos Meas Tech 11:5741-5765. 
Martins V S, Lyapustin A, de Carvalho LAS, Barbosa CCF, Novo EMLM (2017) Validation of high-resolution MAIAC aerosol product over South America. J Geophys Res Atmos 122:7537-7559.

Prospero JM, Glaccum RA, Nees RT (1981) Atmospheric transport of soil dust from Africa to South America. Nature 289:570-572.

Querol X, Tobías A, Pérez N, Karanasiou A, Amato F, Stafoggia M, Pérez García-Pando C, Ginoux P, Forastiere F, Gumy S, Mudu P, Alastueya A (2019) Monitoring the impact of desert dust outbreaks for air quality for health studies. Environ Int 130:104867.

Reid JS, Jonsson HH, Maring HB, Smirnov A, Savoie DL, Cliff SS, Reid EA, Livingston JM, Meier MM, Dubovik O, Tsay SC (2003) Comparison of size and morphological measurements of coarse mode dust particles from Africa. J Geophys Res 108:8593.

Strickland MJ, Hao H, Hu X, Chang HH, Darrow LA, Liu Y (2016) Pediatric emergency visits and short-term changes in $\mathrm{PM}_{2.5}$ concentrations in the US state of Georgia. Environ

397 Health Perspect 124:690-696.

398 Viel JF, Mallet Y, Raghoumandan C, Quénel P, Kadhel P, Rouget F, Multigner L (2019)

399 Impact of Saharan Dust Episodes on Preterm Births in Guadeloupe (French West Indies)

$400 \quad$ Occup Environ Med 76:336-340.

401 Xiao Q, Wang Y, Chang HH, Menga X, Genga G, Lyapustin A, Liu Y (2017) Full-coverage 402 high-resolution daily $\mathrm{PM}_{2.5}$ estimation using MAIAC AOD in the Yangtze River Delta of 403 China. Remote Sensing Environ 199:437-446. 
Table 1 Mean $\mathrm{AOT}_{470}$ values during pregnancy and comparisons according to the place of residence of pregnant women ( $\mathrm{n}=906$, mother-child cohort, 2005-2008, Guadeloupe)

\begin{tabular}{|c|c|c|c|c|c|c|c|}
\hline \multirow[b]{2}{*}{ Place of residence } & \multirow[b]{2}{*}{ mean (sd) } & \multicolumn{3}{|c|}{ Univariate analysis } & \multicolumn{3}{|c|}{ Multivariate analysis ${ }^{\mathrm{a}}$} \\
\hline & & $\begin{array}{c}\text { ß } \\
\text { coefficient }\end{array}$ & $95 \%$ CI & $p$-value & $\begin{array}{c}\text { ß } \\
\text { coefficient }\end{array}$ & $95 \%$ CI & $p$-value \\
\hline \multicolumn{8}{|l|}{ Topography } \\
\hline windward side & $0.189(0.038)$ & Ref. & - & & Ref. & - & \\
\hline leeward side & $0.180(0.035)$ & -0.009 & $-0.017,-0.006$ & $<10^{-4}$ & -0.002 & $-0.017,-0.055$ & 0.81 \\
\hline \multicolumn{8}{|l|}{ Urbanization } \\
\hline capital city and suburbs & $0.186(0.038)$ & Ref. & - & & Ref. & - & \\
\hline rest of Guadeloupe & $0.184(0.028)$ & -0.003 & $-0.010,0.004$ & 0.40 & -0.016 & $-0.036,0.003$ & 0.11 \\
\hline
\end{tabular}

Aerosol optical thickness ( $\left.\mathrm{AOT}_{470}\right)$, confidence interval (CI).

${ }^{a}$ adjusting for time period (semesters) and space (geographical contrast) $\mathrm{x}$ time (semesters) interactions 
Fig. 1 Geographical features of the Guadeloupe archipelago and places of residence of

406 pregnant women (n=906, mother-child cohort, 2005-2008)

407 Each circle represents a mother's place of residence. The location of the air quality monitoring station is indicated 408 by the diamond symbol. The location of the La Soufrière volcano is indicated by the triangle. Pointe-à-Pitre city 409 and its suburbs are identified by the black rectangle.

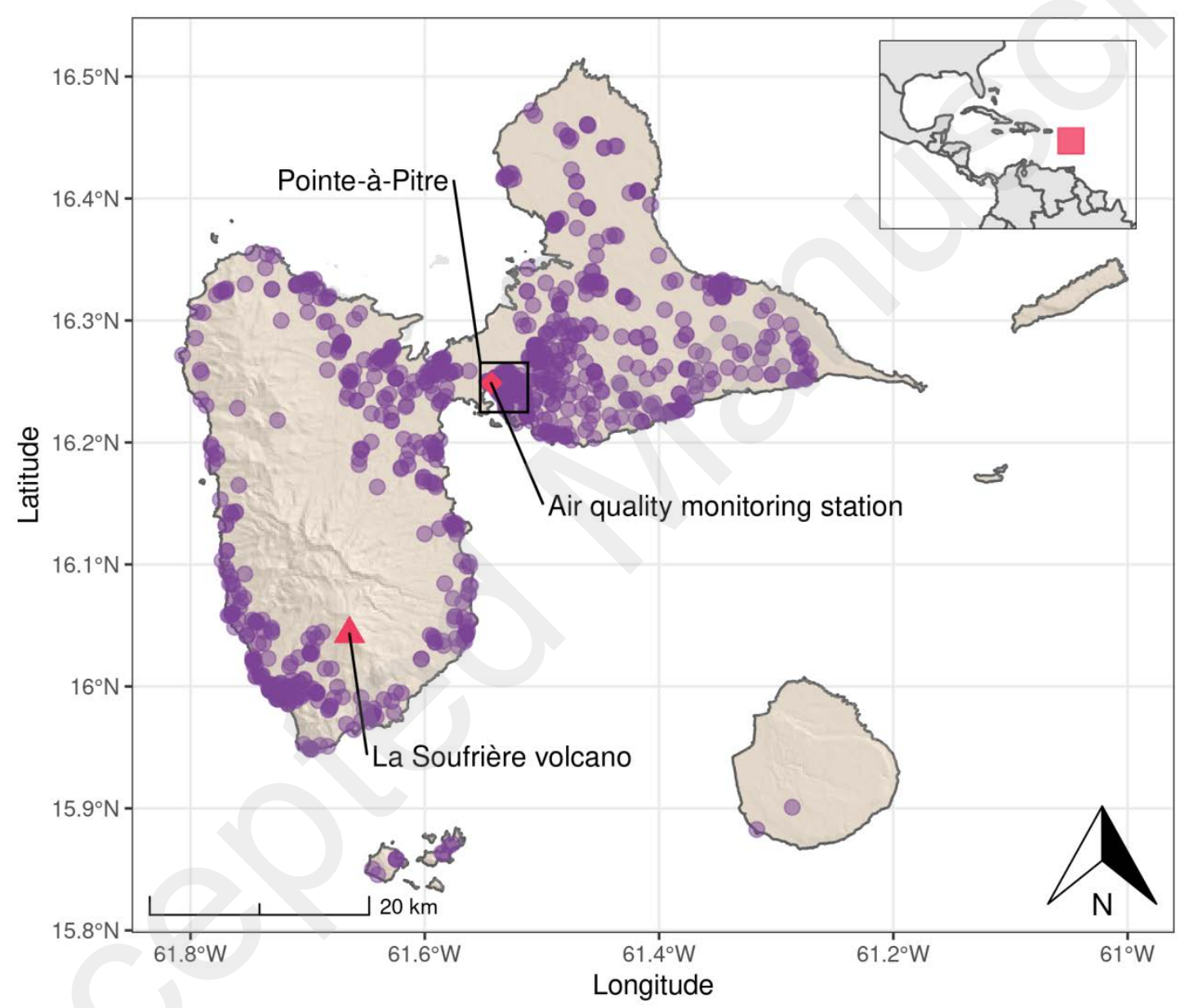


410 Fig. 2 Time series of average daily $\mathrm{PM}_{10}$ concentrations (red line) and average daily AOT 470

411 values calculated from 1,054 1x1 km pixels (green line) (2005-2008, Guadeloupe)

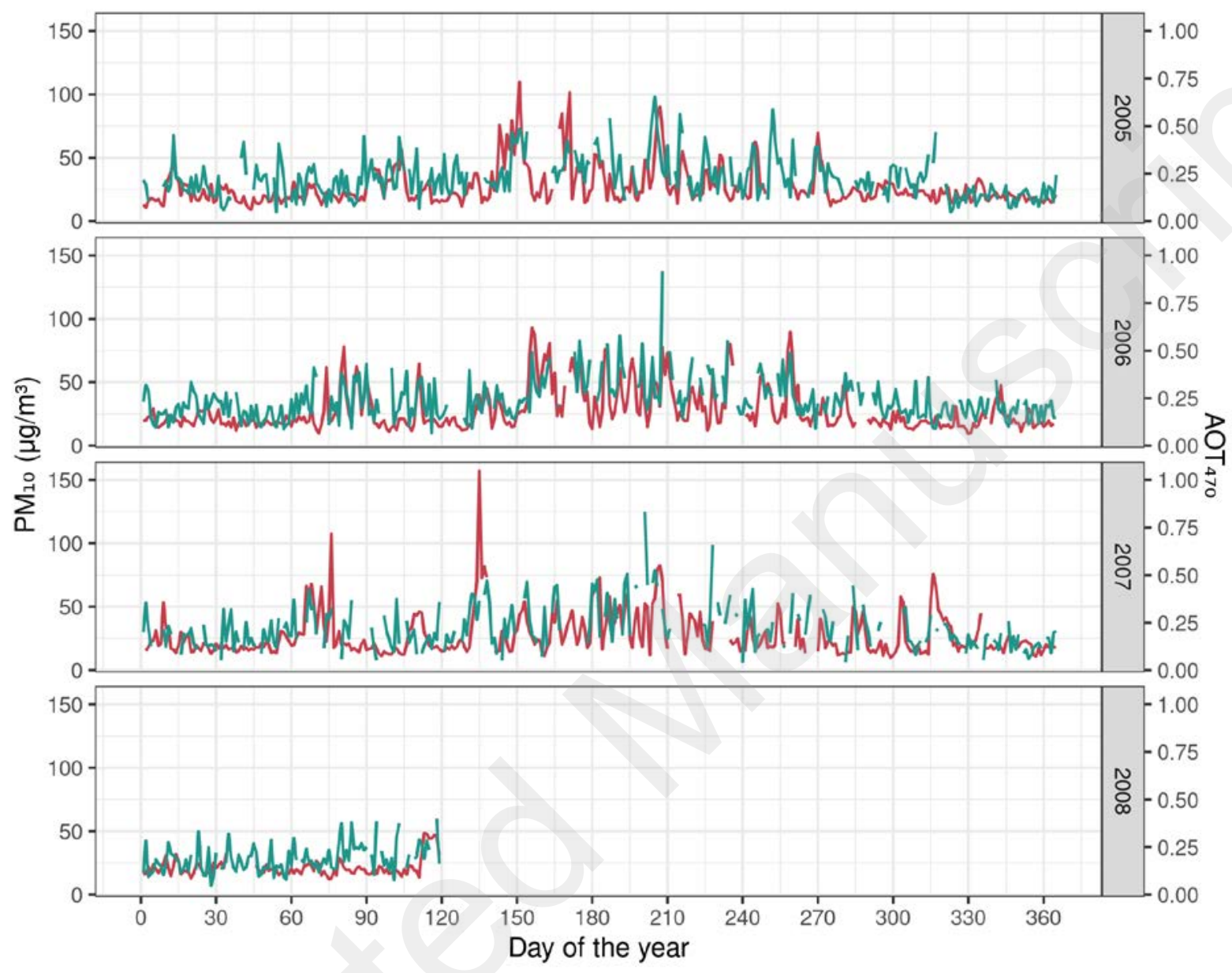


412 Fig. 3 Average AOT $_{470}$ retrievals during pregnancy according to the mother's place of residence

413 (at week 14 of pregnancy) and time period ( $\mathrm{n}=906$, mother-child cohort, Guadeloupe)

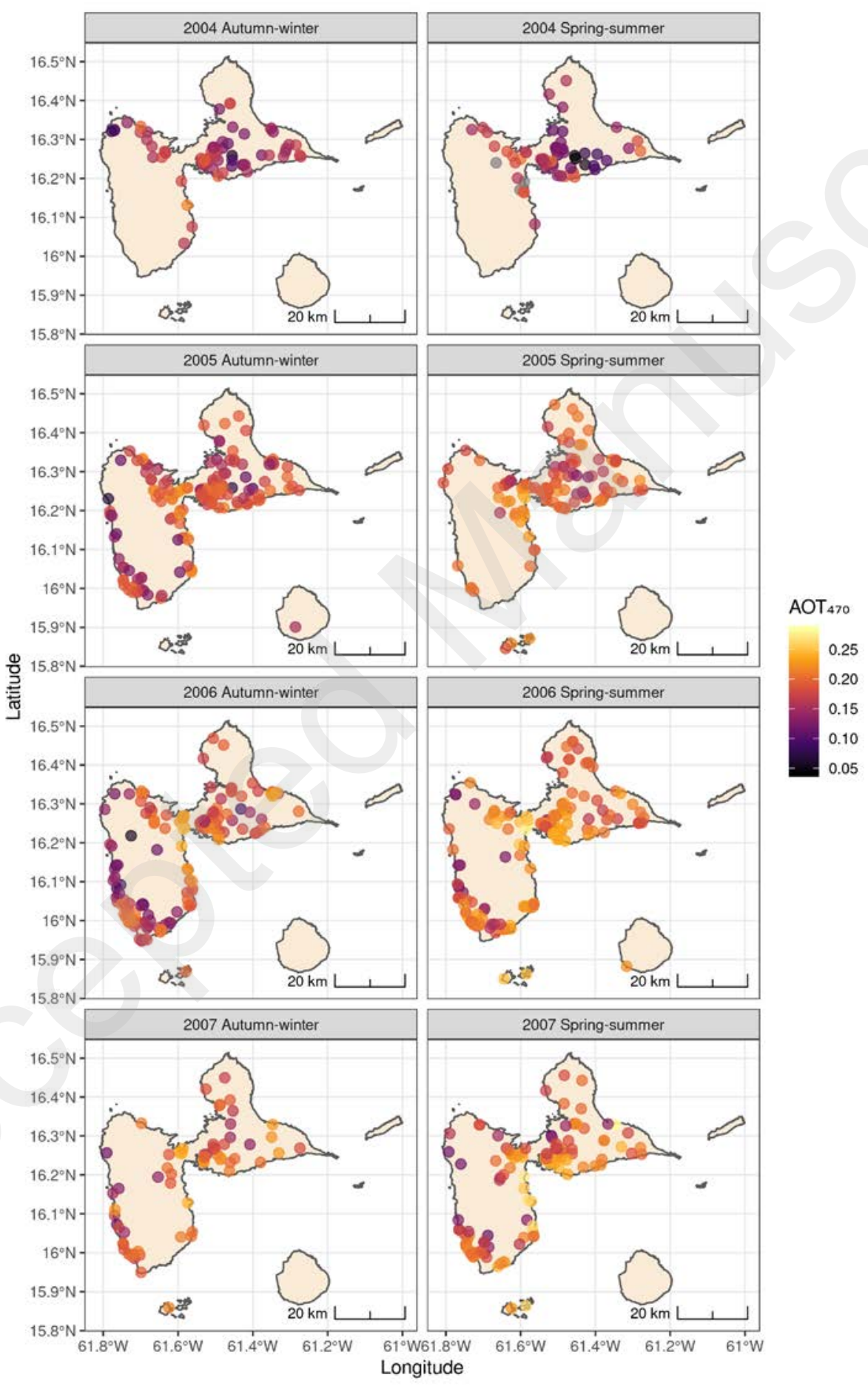


414 Fig. 4 Linear regression between mean $\mathrm{AOT}_{470}$ values and ground-based $\mathrm{PM}_{10}$ concentrations

$415\left(\mu \mathrm{g} / \mathrm{m}^{3}\right)$ during pregnancy $(\mathrm{n}=906,2005-2008$, Guadeloupe $)$

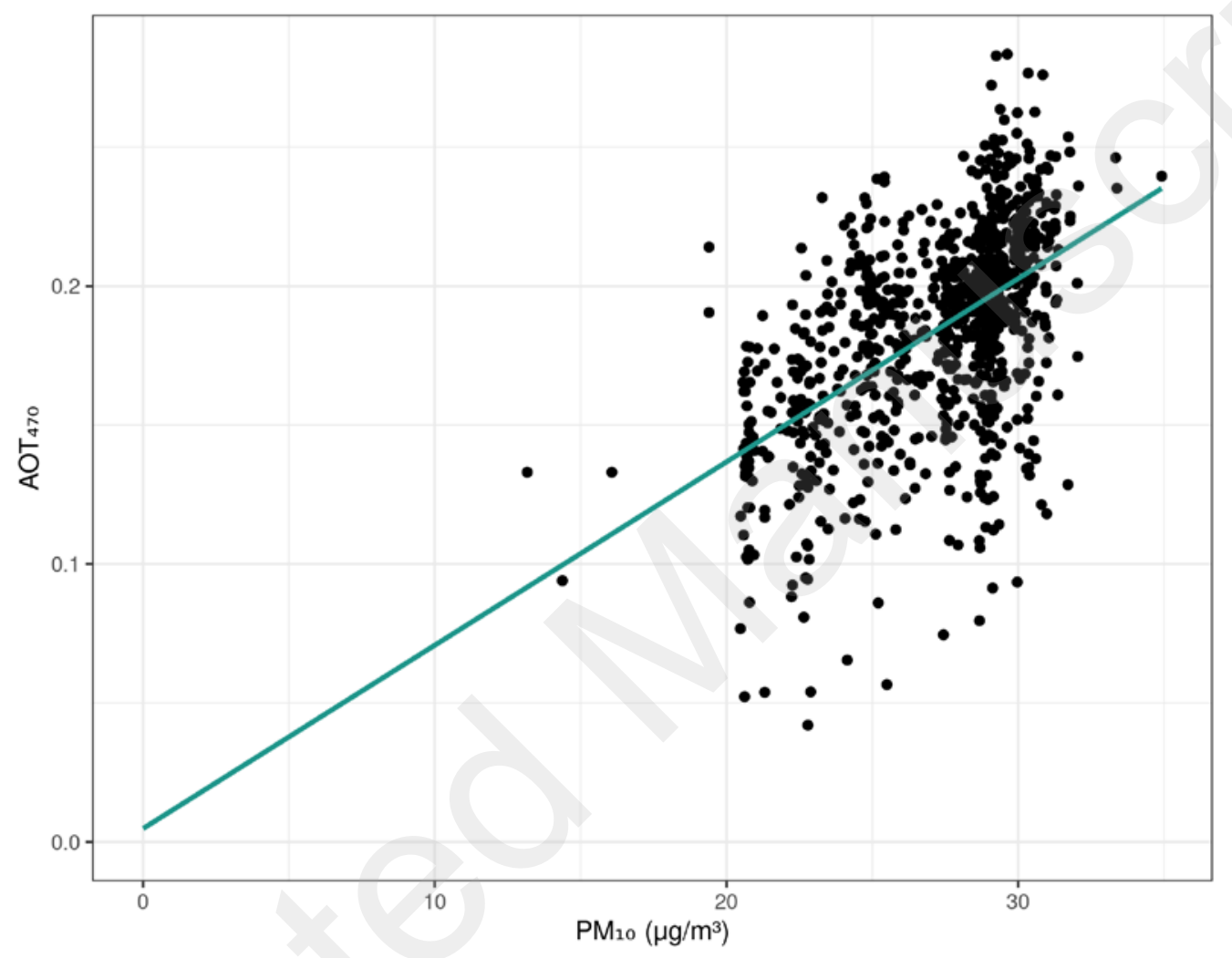

